\title{
Comparing Guided Discovery and Exposition-with-Interaction Methods In Teaching Biology in Secondary Schools
}

\author{
Mr. William Mirasi ${ }^{1}$ \\ Dr. Joseph Osodo² \\ Prof. Israel Kibirige ${ }^{2}$ \\ 1Maseno University, Maseno, Kenya, osodojoey@yahoo.com, \\ 2University of Limpopo, Polokwane, South Africa, Israel.Kibirige@ul.ac.za
}

\section{Doi:10.5901/mjss.2013.v4n14p81}

\section{Abstract}

Guided discovery (GD) method of teaching biology is recommended in secondary schools but many teachers use expositionwith-interaction (EI). GD requires process skills such as experiment design, observation and manipulation of variables to discover answers; whereas El uses lecturing, asking questions and giving notes to learners to memorize content. These two methods have different outcomes on achievement and therefore there is a need to establish their efficacies. The purpose of the study was to compare the effect of the two methods on learners' achievement in secondary schools. Ex post-facto design was used. Target population consisted of 60 biology teachers and 2,172 form 4 students. The study sampled 42 form 4 (Grade 9) biology teachers purposively and 1502 form 4 students randomly. Three instruments were used to collect data: teacherquestionnaire to find out the extent to which GD and El were used; Science Teaching Observation Schedule (STOS) to confirm evidence from the questionnaire and biology stake examination trial results to provide scores. Experts in the department were consulted to determine validity. Quantitative data was analyzed using descriptive statistics such as percentages, frequency and averages and inferential statistics were done using t-test $(p<0.05)$. Results indicated that mean achievement of students taught using GD method was higher than that of the El method. Thus, the use of GD in teaching biology is recommended. The study may be beneficial to educational practitioners, policy makers and researchers to improve performance of learners in biology.

Keywords: Guided discovery, teaching, biology, achievement

\section{Introduction}

Types of learning with strong emphasis on responsibility of the learner particularly GD are gaining popularity over improved traditional forms such as El (Janine, Ton de, \& Wouter, 2004; Ibe, 2013). In Kenya, the secondary school syllabus (2005) recommends GD but most biology teachers use El method. The El method is characterized by deficiencies in practical skills (Wabuke et. al., 2013). A question therefore arises as to why El is being used by most teachers despite GD recommendation. Nwagbo (1999, as cited in Akinyemi \& Afolabi, 2010) explains that in GD, the teacher provides illustrative materials for students to study on their own. Leading questions are then asked by the teacher to enable students think and provide conclusions through adoption of science processes. If the learner is allowed to discover relationships and methods of solutions by himself/herself, make his/her own generalizations and draw conclusions from them, s/he may then be prepared to make wide applications of the material learned (Akinyemi \& Afolabi, 2010; Braund et. al., 2013). Ibe (2013) concurs that use of GD method results in enhanced comprehension of concepts in learners. According to Moore (2008), El emphasizes presenting ideas and information meaningfully and effectively. The teacher then checks for comprehension by asking questions to asses students' understanding of the material explained or studied. GD and El aim at enhancing learning among students but differ in their instructional approaches. GD requires process skills such as experiment design, observation and manipulation of variables to discover answers; whereas El uses lecturing, asking questions and giving notes to learners to memorize content.

Mayer (2004) recommends using GD because it helps students meet two important criteria for effective learning. Firstly, activating or constructing appropriate knowledge to be used in making sense of new incoming information. Secondly, integrating new incoming information with appropriate knowledge base. On the other hand, El is supported by Clark and Mayer (2008). This is because El involves questioning, and when students answer questions and receive 
feedback, they process materials more deeply and store material in a more retrievable form. There is engagement which increases students' attention so that they are more likely to encode the presented material, and also metacognition. This implies that answering questions help students to gauge their level of understanding. This allows time to allocate their cognitive processing to aspects of the lesson which they seem not to understand.

Various scholars have different accounts why El is more prevalent in schools than GD. According to Shing-fong, Yin-kum Law and Mark Shin-kee Shum (2009), teachers' resistance is expected because the new practice bears little resemblance to the practices they had experienced as students themselves. However, according to lbe (2013), GD does not necessarily yield better education outcomes though few studies have been conducted to authenticate this. In Nyakach district, students' performance in Kenya Certificate of Secondary Education (K.C.S.E) biology is low (mean score of 5.05 out of a possible maximum mean of 12.00 in 2010) despite the biology syllabus (2005) recommending the use of GD. The study therefore intended to compare the effect of the two methods on learners' achievement in public secondary schools within Nyakach district.

\section{Statement of the Problem}

The government of Kenya, through the ministry of education curriculum developers recommends GD method of teaching biology in secondary schools yet reports indicate that most teachers in the field generally use El. For example, situation analysis carried out by Center for Mathematics, Science and Technology in Africa (CEMASTEA) in 2009, found out that most of the teaching was teacher centered. In Kenya, performance in biology is poor (Republic of Kenya sessional paper, No.1 of 2005, p.44; Wabuke et. al. 2013). Nyakach district, for instance, has recorded low mean scores in biology in Kenya Certificate of Secondary Examinations (KCSE) for the last three years (Table 1).

Table1. KCSE mean score in Biology in Nyakach district from 2010-2012 (Source: District Education Officer's office, Nyakach district).

\begin{tabular}{|lc|}
\hline Year & KCSE mean score in Biology \\
\hline 2010 & 5.05 \\
2011 & 5.07 \\
2012 & 5.10 \\
\hline
\end{tabular}

Poor performance in Nyakach district may be attributable to the method used in teaching biology. Thus, there is a need to address the issue of poor performance in order to improve the general level of education in the district. This study therefore intended to find out if the use of GD was superior to El in order to sensitize teachers on a better method of teaching biology. The objectives of the study were to: 1) establish the extent to which GD and El were being used in teaching biology; and 2) determine the effect of GD and El methods on students' performance. The research questions used in this study were: 1) To what extent are GD and El being used in teaching biology?; and 2) What is the effect of $\mathrm{GD}$ and $\mathrm{El}$ methods on students' performance?

\section{Methodology}

\subsection{Research design}

The research adopted ex post-facto design targeting data from classroom transactions. Ex post-facto was suitable for this study because it determines the effect of an existing state of affairs. The researcher therefore compared the effect of GD and El on learners' achievement in secondary schools in Nyakach district.

\subsection{Population and sampling}

The target population consisted of 60 biology teachers and 2,172 from form 4 (Grade 9) students of the year 2013. The study purposively sampled 42 biology teachers and randomly selected 1502 form 4 (Grade 9). The criteria for purposive sampling were: (1) teachers who were teaching form 4 biology students at the time of the study, (2) professional graduate or diploma trained teachers. These teachers were purposively categorized into GD and El groups based on the 
approach they use in their schools.

\subsection{Research Instruments}

Teacher-questionnaire were issued to the sampled teachers to find out the extent to which GD and El methods were being used in teaching biology. The Science Teacher Observation Schedule (STOS) was used to confirm evidence from the questionnaire. The schedule was divided into two main parts: 'teacher talk' and 'learners' initiated and maintained talks and activities'. Teacher talk consisted of seven categories of questions, four statements and four directives. Learners' activities were subdivided into eight categories where they either sought information or referred back to the teacher. The schedule was concerned with the cognitive aspects of science teaching: recalling facts and principles, formulating hypothesis, designing experimental procedures, observation, interpretation of data, and making inferences. A record of lessons was produced by noting when any of the 23 intellectual transactions occurred in each three-minute "time sampling unit". Thus, in a lesson lasting 60 minutes, there would be 20 sampling units $(20 \times 3=60)$. In each of these, one or more transactions may have occurred and would be noted. However, if one kind of transaction occurred for a number of times in any one time unit, all occasions after the first were ignored. Each category of behavior was recorded only once, on the first occasions on which it occurred, during any given three-minute time unit. Thus, the overall count for any category represented the minimum frequency of occurrence of that behavior. In order to estimate the frequency of use of any category, the fraction was calculated using Eggleston, Galton \& Jones' (1976) equation as shown:

No of time units in which behavior occurred $\times 100$

Total number of time units observed

The third instrument used was biology stake examination trial results (2013) to provide scores which differentiated GD from El group. Experts in the department were consulted to determine the validity of the instruments. Piloting was done to determine reliability of the questionnaire through test-retest method.

\subsection{Data collection procedure}

Before any investigation into the research problem was undertaken, a consent letter from the faculty of education at Maseno University was obtained. The letter was then used by the researcher to obtain an introductory letter and permission from the District Education Officer (DEO) to conduct research in the district. An introductory letter was written by the first author to principals and concerned biology teachers of the sampled schools. This was an information letter concerning the intended visit, informed consent and issuing of data collection instruments. Arrangements were then made with the biology teachers for a suitable date to collect data. The selected 42 (17 GD and $25 \mathrm{IE})$ teachers were then randomly sampled by applying the 33\% rule (Gay, 1981) to get 14 teachers (6 GD and $8 \mathrm{EI})$ for the science teaching observation schedule as a refinement to the results from questionnaire. Lessons lasting 90 minutes were observed as guided by the STOS adapted (Eggleston, Galton \& Jones, 1976). Quantitative data was analyzed using a descriptive statistics such as percentages, frequency and averages and inferential statistics were done using t-test $(p<0.05)$.

\section{Results and Discussion}

\subsection{Extent to which GD and El teaching methods were used}

The first part of the research was to determine the extent to which GD and El were being used in teaching biology. To achieve this objective, teachers were asked to react to several statements as well as to state the strategy or approach they normally used in teaching biology. Out of a total number of 42 teachers, 17 used GD whereas 25 used El (Table 2).

Table 2. The extent to which GD and El were used in teaching biology

\begin{tabular}{lc}
\hline Category & Number of Teachers (\%) \\
\hline GD & $17(40.5 \%)$ \\
EI & $25(59.5 \%)$ \\
\hline
\end{tabular}


The results of the STOS analysis of individual participants' classroom intellectual transactions in form of talk and initiated activity are shown in Table 3.

Table 3. Frequencies of use of STOS categories by the respondents (incidence per 100 time sampling units)

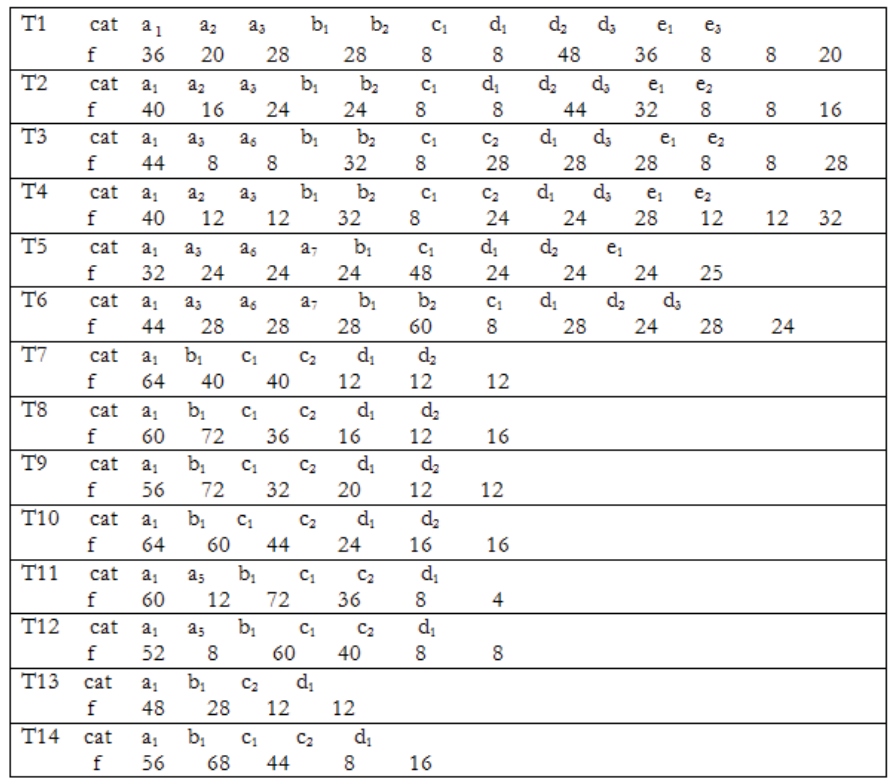

Key

Cat- category

f- incidence/100 sampling units

T1- Teacher one T2- Teacher two T3- Teacher three T4-Teacher four

T5- Teacher five T6- Teacher six T7- Teacher seven T8- Teacher eight

T9- Teacher nine T7- Teacher ten T11- Teacher eleven T12- Teacher twelve

T13-Teacher thirteen T14-Teacher fourteen

1a Teacher asks a question (or invites comments) which are answered by:

$a_{1}$ recalling facts and principles

$\mathrm{a}_{2}$ applying facts and principles to problem solving

as making hypothesis and speculation

$a_{4}$ designing experimental procedure

as direct observation

$a_{6}$ interpretation of observed and recorded data

at making inferences from observation data

1b Teacher makes statements:

$b_{1}$ on facts and principle

$\mathrm{b}_{2}$ of problems

$b_{3}$ of hypothesis or speculation

$\mathrm{b}_{4}$ of experimental procedure

1c Teacher directs pupils to sources of information for the purpose of:

$\mathrm{C}_{1}$ acquiring or confirming facts and principles

$\mathrm{C}_{2}$ identifying or solving problems

$c_{3}$ making inferences, formulation or testing hypothesis

$\mathrm{C}_{4}$ seeking guidance on experimental procedure

$2 \mathrm{~d}$ Pupils seek information or consult for the purpose of:

$\mathrm{d}_{1}$ acquiring or confirming facts or principles 


\section{$\mathrm{d}_{2}$ identifying or solving problems}

$d_{3}$ making inferences, formulating or testing hypothesis

$\mathrm{d}_{4}$ clarifying experimental procedures

2e Pupils refer to teachers for the purpose of:

$\mathrm{e}_{1}$ acquiring or confirming facts or principles

$\mathrm{e}_{2}$ seeking guidance when identifying or solving problems

$\mathrm{e}_{3}$ seeking guidance when making inferences, formulating or testing hypothesis

$\mathrm{e}_{4}$ seeking guidance on experimental procedures.

An examination of Table 3 reveals the following patterns: in most cases, there was a high frequency of teachers' questions in categories $a^{1}-a^{7}$, high frequencies of teacher statements in categories $b^{1}-b^{2}$ and of teacher directives in categories $c^{1}-c^{2}$ supported by pupils initiated and maintained talk and activities in categories $d^{1}-d^{4}$ and $e^{1}-e^{2}$. The transactions of $\mathrm{T} 1, \mathrm{~T} 2, \mathrm{~T} 3, \mathrm{~T} 4, \mathrm{~T} 5$ and $\mathrm{T} 6$ are characterized by the unique features of $\mathrm{a}^{3}$, that is, teachers' questions answered by constructing hypothesis, and $\mathrm{b}^{2}$, teachers' statements of problems. Compared to T7, T8, T9, T10, T11, T12, T13 and T14, these teachers showed a de-emphasis of the informational aspects of science, in favor of problem-solving and speculative processes. The transactions of teacher T1 and T2 in particular, uniquely stand out in having frequencies distribution in the $d$ and e major categories. A fitting characteristic orientation of this group of teachers would be the 'pupil-centered' approach.

Teachers T7, T8, T9, T10, T11, T12, T13 and T13 transactions seemed singular in their infrequent use of teacher questions (categories $a^{2}-a^{7}$ ) and in having the highest frequency (T7 and T10) of all categories of $a^{1}$, that is, teacher questions demanding recall of facts and principles. They are further characterized by having relatively high incidences of teacher statements of facts (category $b^{1}$ ) and teacher directions to sources for fact finding (category $c^{1}$ ). The relatively infrequent use of pupil initiated and maintained talk or activity suggests passive, attentive classes, offering little in response to teacher fact-oriented talk and activity. The teacher image arising in this transaction is that of a contentoriented transmitter of factual information (teacher-centered). In summary, teachers $\mathrm{T} 1, \mathrm{~T} 2, \mathrm{~T} 3, \mathrm{~T} 4, \mathrm{~T} 5$, and T6 are the GD group (42.8\%) while T7, T8, T9, T10, T11, T12, T13 and T14 are the El group (57.2\%).

The results of the study revealed that the extent of using El in teaching biology was more predominant than GD. These findings indicate that teachers using El method in teaching biology were more than those using GD. This could be attributed to the fact that GD was a relatively new approach compared to El. According to Shing-fong, Yin-kum Law and Mark Shin-kee Shum (2009), teachers' resistance is expected because the new practice bears little resemblance to the practices they had experienced as students themselves. As Petty (2008) noted, GD method is difficult for an inexperienced teacher to use. Findings from previous studies (APHRC, 2010; CEMESTEA, 2009; Omany et. al., 2007; Chirwa \& Njuge, 2004) concur with the current study where most teaching was based on teacher centered method. However, the current study further observed the extent of using GD and El in teaching biology instead of general classroom observation of teaching methods. The current study also employed different methodological approaches by adopting the Galton and Aggleston (1979) lesson observation schedule (STOS). The schedule assisted in establishing the extent of using El as $57.2 \%$ and $42.8 \%$ for using GD (Table 2).

\subsection{Effect of GD and El methods on students' performance}

Analysis on Table 4 reveals that the mean score of the GD group on biology stake examination trials (2013) was 50.08 while that of El group was 40.12. This indicates that there were variations between the mean score of students taught biology using GD method and those taught using El method. The mean score for biology stake examination trials (2013) of the GD group was more than that of the El group. Therefore, the mean academic achievement of students taught biology using GD method was higher than that of the El group.

Table 4. Means, Standard deviations and gain in achievement of GD and EI

\begin{tabular}{|c|c|c|c|c|c|}
\hline & Teach & $\mathrm{N}$ & Mean & Std. Deviation & Std. Error Mean \\
\hline \multirow{2}{*}{ Score } & GD & 17 & 50.08 & 6.65 & 1.61 \\
& El & 25 & 40.12 & 4.10 & 0.82 \\
\hline
\end{tabular}

Analysis in Table 5 shows that students taught using GD method performed significantly better than those taught using El on the same biology stake examination trials (2013). The analysis reveals that an independent sample t-test 
conducted to compare the biology stake examination trials (2013) scores for GD and El group is significant. The calculated $t$-value for the main effect was 5.50. This value is greater than the t-critical value of 0.00 . Therefore, there was a significant difference between the mean of students taught using GD method and those taught using El.

Table 5. Analysis of independent t-test for KCSE mock scores (2013) of GD and El groups ( $p=0.005)$

\begin{tabular}{|c|c|c|c|c|c|c|c|c|c|}
\hline & \multicolumn{3}{|c|}{$\begin{array}{c}\text { Levene's Test for } \\
\text { Equality of Variances }\end{array}$} & \multicolumn{9}{|c|}{ t-test for Equality of Means } \\
\cline { 2 - 10 } & $\mathrm{F}$ & Sig. & $\mathrm{t}$ & Df & $\begin{array}{c}\text { Sig. (2- } \\
\text { tailed) }\end{array}$ & $\begin{array}{c}\text { Mean } \\
\text { Difference }\end{array}$ & $\begin{array}{c}\text { Std. Error } \\
\text { Difference }\end{array}$ & $\begin{array}{c}\text { 95\% Confidence Interval of } \\
\text { the Difference }\end{array}$ \\
\hline Score & & & & & & & & Lower & Upper \\
\hline $\begin{array}{c}\text { Equal variances } \\
\text { assumed } \\
\text { Equal variances } \\
\text { not assumed }\end{array}$ & 11.04 & .00 & 6.01 & 40 & .00 & 9.96 & 1.66 & 6.61 & 13.31 \\
\hline
\end{tabular}

This study compared the effect of GD and El methods in teaching biology on learners' achievement in secondary schools. The results in Table 4 showed that the mean achievement of students that were taught biology using GD method was higher than those students taught using_the El method. Table 5 also indicated that those taught using GD method performed significantly better than those taught with El. The performance of students taught using GD method might be attributed to the fact that GD has the benefit of increasing intellectual potency by enhancing the learners' ability to organize and classify information. Information imbibed through GD becomes firmly embedded in the cognitive structures of the learners thereby facilitating retrieval. Also, GD teaching is based on the fact that learning occurs as learners get_actively involved in a process of meaningful and knowledge construction rather than passively receiving information. Learners are the makers of their own learning; the teacher only facilitates and provides learners with experiences that allow them to use science process skills such as experimental design, observation and manipulation of variables. These finding tally with the results of Bundrick (1968), Kersh (1998), Omuirhiren (2002), Akinbobola (2008), Akiyemi et. al. (2010) and Ibe (2013) that GD approach was effective in enhancing achievement and retention of students in science subjects. On the other hand, the findings disagree with that of Klar and Nigram (2004, as cited in Kirschner et. al., 2006) and Clark et. al. (2012) who found that direct instruction involving considerable guidance, including examples, resulted in vastly more learning than GD. This disagreement could be because Klar and Nigram tested content knowledge (recalling facts and principles) while the present study tested understanding (having content knowledge and skills pertaining to that knowledge). Clark et. al. (2012) findings used partially GD and El methods of instruction.

\section{Conclusions and Recommendations}

The study concluded that El was commonly used in teaching biology than GD in Nyakach District despite the syllabus recommending the use of GD. This may be true because GD is a relatively new teaching method that bears little resemblance to the practices most teachers experienced as students themselves. It could therefore be concluded that most teachers in Nyakach District are not yet adequately prepared to use GD. Learners who were taught using GD performed much better than their counterparts who were taught using El. As such, the study concluded that GD was very effective in teaching biology. The study recommends that biology teachers should use GD method in order to engage students in understanding concepts in biology rather than using El which often results in rote learning and memorization. It is also recommended that the government should upgrade infrastructure and equip laboratories in order for learners to be actively involved in learning. In-service training and workshops should be strengthened so as to enable science teachers to effectively use new teaching practices such as GD. Further research is recommended on teachers' perspective on the use of GD method in order to find out why most teachers rarely use GD method. Also, similar research using large samples is recommended by adopting experimental design instead of ex post-facto to ascertain the current findings.

\section{References}

Akinbobola, A.O. (2008). Facilitating Nigerian physics students' attitude towards The concept of heat energy. Scientia Paedagogica. Experimentalis, 45, 353-366. 
Akiyemi, O.A., \& Folashade, A. (2010).Constructivist practices through guided discovery approach: The effect on student's cognitive achievement in Nigeria senior secondary school physics. Eurasian J. Physics and Chemistry Education, 2(1):16-25.

Braund, M., Bennett, I., Hampden-Thompson, G. (2013). Teaching approach and success in A-biology: Comparing student attainment in context-based, concept-based and mixed approaches to teaching A-level biology. Report to the Nuffield Foundation. York: Department of Education, University of York.

Bundrick, C.M. (1968). Comparison of two approaches of teaching of selected topics In plane analytic geometry. Dissertation. Ann Abor: University microfilms.

Clark, R. E., Kirschner, A. P. \& Sweller, J. (2012). Putting students on the path to learning: the case for fully guided instruction. American Educator, 36(1), 8-13.

Clark, R. C. and Mayer, R. E. (2008). Learning By Viewing Versus Learning By Doing: Evidence-Based Guidelines For Principled Learning Environments. Wiley, InterScience.

Eggleston, J.F., Galton, M.J \& Jones, M.E. (1976). Processes and Products of Science Teaching. Schools council Research Studies, London: Macmillan.

Gay, L. R. (1981). Educational Research. London: Macmillan.

Ibe, H. N. N. (2013). Effects of guided-inquiry and expository teaching methods on senior secondary school students' performances in Biology in Imo State. Journal of Education Research and Behavioral Sciences, 2(4),15-57.

Janine, S., Ton de, J., \& Wouter, R.van J. (2004). The effects of discovery learning And expository instruction on the acquisition of definitional and intuitive knowledge. Computer Assisted Learning, 20, 225-234.

Kersh, R. S. (1998). The adequacy of meaning and explanation for superiority of Learning by independent discovery. J. Educational Psychology, 49, 282-292.

Kirschner, P.A., Sweller, J., \& Clark, R.E (2006). "Why minimal guidance during Instruction does not work: an analysis of the failure of constructivist discovery Problem based, experiential and inquiry-based teaching." Educational Psychologist,41 (2): 75-86.

Omwirhiren, C.M. (2002). The effect of guided discovery and traditional methods on the achievement of SSCE students in the chemical energetic. African J. Research in Education, 2, 21-24.

Mayer, R. (2004). "Should there be a three-strike rule against pure discovery learning? The case for guided methods of instruction."American Psychologist, 59(1): 14-19.

Nwagbo, C. (1999). Effects of guided discovery and expository teaching methods on the attitudes towards biology students with different level of scientific literacy. J. Science Teachers Association of Nigeria (STAN), 36, 43-51.

Petty, G. (2008). Teaching today. United Kingdom: Nelson Thomas.

Republic of Kenya, (2005). A policy framework for Education, Training and Research.Sessional paper of 2005, Nairobi.

Shui-fong, L., Yin-Kum, L., \& Mark, S.S. (2009). Classroom discourse analysis and educational outcomes in the era of education reform Educational Psychology, 79, 617-641.

Wabuke, J. M., Barmao, C. C. \& Jepkorir, M. (2013). Overcoming Teacher Related Challenges to Performance in Biology subject among Secondary School Students in Eldoret Municipality, Kenya. Journal of Emerging Trends in Educational Research and Policy Studies, 4(1):79-87. 
